International Journal of Engineering \& Technology, 7 (4.3) (2018) 185-190
International Journal of Engineering \& Technology
SPC
Website: www.sciencepubco.com/index.php/IJET
Research paper

\title{
Agricultural Cargo Transportation Logistics System Development
}

\author{
N. Napkhonenko ${ }^{1 *}$, D. Zagirniak ${ }^{2}$, M. Karaeva ${ }^{3}$ \\ ${ }^{1}$ Federal state budget educational institution of higher professional education "Platov South-Russian State Polytechnic University \\ $(N P I) "$, \\ ${ }^{2}$ Kremenchuk Mykhailo Ostrohradskyi National University, \\ ${ }^{3}$ Federal state budget educational institution of higher professional education "Platov South-Russian State Polytechnic University \\ $(N P I) "$, \\ *Corresponding author E-mail: naphonenko@gmail.com
}

\begin{abstract}
The urgency of transportation organization improvement in the system of agricultural products delivery to the country's population under conditions of import substitution is substantiated here. The article proposes to use the logistic approach. The advantage of the approach is that it combines and considers the processes of harvesting, transportation and distribution of goods in reciprocal relationship; and on this basis the concept of united harvesting, transportation and distribution complex (HTS) is introduced. The main organizational schemes for agricultural products delivery from the producer to the places of consumption are considered. Mathematical formulation of the vegetables transportation system optimization at HTS complex is performed based on the inclusion of receiving and classification units (RCU) in the logistics chains of delivery from the producer to the places of agricultural products consumption. An optimized multi-factor economic and mathematical model is proposed. It allows to identify RCU rational locations and their capacity, to calculate the number of road transport vehicles necessary to deliver vegetable cargo in full, provided that the recipients are optimally assigned to the product suppliers and available vehicles are optimally distributed for all modes of transport. Methods of the process main characteristics calculation are described.
\end{abstract}

Keywords: harvesting-transportation-realization (HTS) complex; logistics approach; receiving and classification unit (RCU), road transport vehicle, transportation scheme.

\section{Introduction}

Road transport functioning in modern conditions is affected by a number of objective factors, including business environment of transportation industry and consumers' economic conditions, transport services market formation, intensification of competition between transport enterprises and certain types of transport. Transport system reforms, its problems and new approaches development to transportation organization and management have been aggravated by the crisis caused by introduction of sanctions. It should be emphasized that any operation that is not part of the transportation process, but related to its preparation and implementation, such as cargo packing and loading-unloading, packaging and marking, intermediate storage, etc., should be attributed to transportation services. Under current conditions, this list of services should be supplemented with marketing, commercial, information, insurance services, etc. Still, motor transport delivering cargoes to various industrial enterprises, including agricultural ones, is part of the commodity circulation system which is referred to as logistics.

The topicality of logistics approach to solving the problems of production organization and production enterprises interaction, agricultural products processing and their delivery to the country's population is determined by the transition from the seller's market to the consumer's market, which requires a flexible response of production and retail systems to rapidly changing priorities of consumers. At the same time, the use of logistics approach allows to unite and consider the processes of harvesting, transportation and sale as a united harvesting, transportation and distribution complex (HTS) [1, 2, 3].

The common practice for road transport industry is for transportation companies to be assigned to consignees. In such practice there is only a direct link between these objects and cargo flows, and optimal criterion is to ensure minimum costs for the products delivery. However, the choice of optimal freight flows is limited by road transport vehicles availability, specified location and technological characteristics of the corresponding production facilities.

Significant economic effect in solving this issue can be achieved if new links are added to the system of agricultural cargo delivery to consumers, namely: receiving and classification units (RCU). In this case, it is assumed that the region or the transport units concerned are sufficiently equipped with road transport vehicles and loading/unloading equipment for agricultural products; access roads are also considered available. Production units (facilities) are created in the locations where agricultural produce is classified, cargo consignments are formed, primary processing is performed if necessary, etc. However, RCU becomes the main correspondent when transporting goods according to a chosen scheme. Freight flows, in their turn, play a determining role at their rational location, capacity and operating mode [4-10].

Possible schemes for vegetable cargo transportation can be classified as the following groups [11-14]: 
1. Transportation between the field and RCU should be considered as on-farm transportation. It is advisable to use tractors with trailers and light-duty trucks, which are mainly the vehicles owned by agricultural enterprises. In the event of vehicles shortage at collective and/or private farms (hereinafter referred to as "agricultural enterprises"), third-party vehicles are to be involved in transportation. Thus, the delivery of vegetables to an RCU is characterized by traffic patterns I-III (Fig. 1).

The difference between schemes II and III lies in the fact that road transport vehicles of motor transport enterprises (MTE) for the period vegetable cargo transportation in the first case are assigned to agricultural enterprises, and in the second - to RCU.

2. For schemes IV-VII (Fig. 1), vegetables delivery from RCU directly to the consignee is typical. Transportation is performed by road transport vehicles regardless their affiliation.

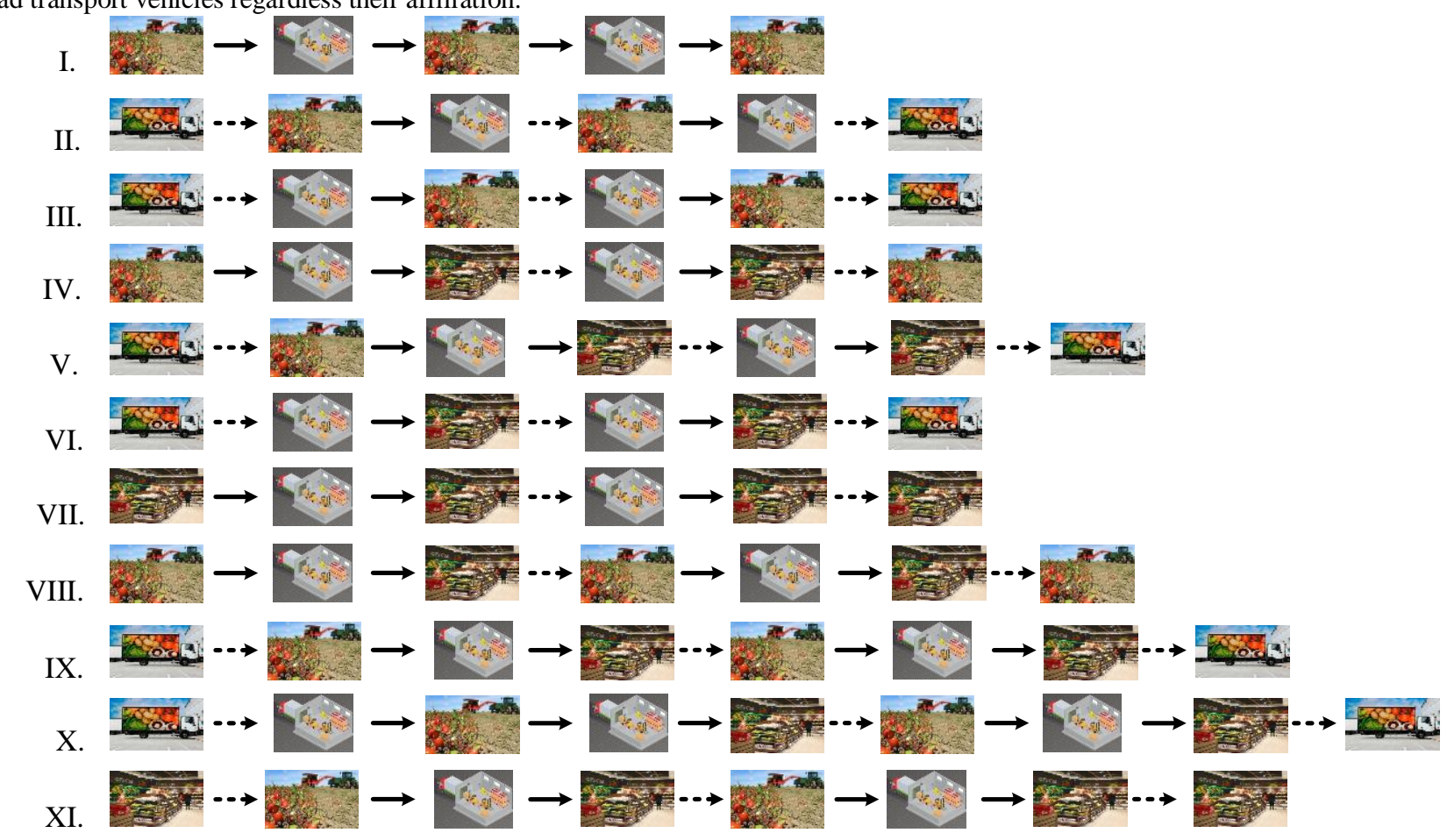

Fig. 1: Schemes of different owners' motor vehicles movement in HTS complex system
At the same time, during the planned period, the assigned vehicles are loaded at the assigned RCU, and at the end of the harvesting period they return to their permanent owners' locations.

Only for scheme IV, the initial and final transportation trips are on-farm, all others are preformed outside the production zone.

3. Schemes VIII-XI (Fig. 1) are used in the cases when a significant quantity of vegetables is submitted for transportation after manual and semi-mechanized methods of harvesting, when it is possible to combine cleaning and sorting processes. Then a part of vegetables can be delivered to the consignee directly from the field. However, in order to avoid disagreements on the quality of shipped products, it is necessary to ensure that it is accepted by the recipient at the place where the cargo consignments is formed. The described schemes VIII-XI are shown in Fig. 1.

$\rightarrow-$ transportation of containers and empty run of road transport vehicles.

Economic-mathematical model of transport process optimization in HTS complex system is multifactorial, cumbersome and laborconsuming in terms of collecting and preparing primary information. At the same time, it is universal and suitable for multiple uses. As a result of its implementation, the following is possible to:

1) identify rational locations of RCU and their capacity. This task is solved once when choosing the RCU location in the region $[10,15]$;

2) calculate the number of vehicles necessary for each planned period, to perform vegetables transport in full, provided the recipients are properly assigned to the product suppliers and the distribution of available vehicles for all traffic schemes is optimal. Significant amount of information is introduced into the model at the initial stage of its design and remains unchanged for all subsequent calculations.

\section{Material Properties}

Mathematic model of road transport process in HTS system is based on the following: annual production of vegetables $(p=1 \ldots P)$ by agricultural enterprises of the region $(k=1 \ldots K)$ :

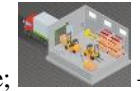

$\mathrm{RCU}$;

RCU; - MTE; $\rightarrow$ - vegetables transportation;

$$
Q=\sum_{k=1}^{K} \sum_{\rho=1}^{P} Q_{k p}
$$

where $Q_{k p}$-is the annual output of $p^{\text {th }}$ produce at the $k^{\text {th }}$ enterprise. Vegetables must be delivered to $n$ recipients $(n=1$ to $N)$.

To transport vegetables in full, road transport vehicles of agricultural enterprises and of other transport owners are used.

Then the participants of HTS complex have vehicles of $s$-type $(s=1 \ldots S)$ available in the quantity of $A_{\kappa s}, A_{n s}, A_{j s}$ units, respectively, at $k^{\text {th }}$ farm (private or collective), for $n^{\text {th }}$ recipient and $j^{\text {th }}$ MTE. Loading of vehicles is carried out directly in the field, plantation or at $i^{\text {th }} \mathrm{RCU}$ ( $i=1$ to $\left.I\right)$, location of which is predetermined.

A characteristic feature of MTE road transport vehicles system is the presence of empty runs at the beginning and at the end of each period. Due to the fact that empty runs cover incomparably shorter distances than the distances covered by road transport vehicles along the transportation routes during the period of transportation, they can be neglected when economic-mathematical model (EMM) is designed.

Harvesting period, depending on the harvesting operations intensity and, consequently, vegetables arrival to RCU, is divided into $t$ periods ( $t=1 \ldots T) D$ days each. Typically, at agricultural production planning stage, $D$ is equal to 10 days, i.e. $D=10$. 
Transportation process is characterized by a number of parameters. The main parameters are the following: the required number of road transport vehicles necessary to perform transportation in full; the number of trips to be done for all types of vehicles in each scheme, and the corresponding output per trip for transportation of different vegetable types; the delivery cost for one (1) ton of produce along the route, etc. [7, 13, 14].

To design the transport process EMM in HTS complex, the following captions are introduced $x_{\text {êisp }}^{\mathrm{II}}, x_{\text {jêisp }}^{\mathrm{II} t}, x_{\text {jiêsp }}^{\mathrm{III} t}, x_{\text {êinsp }}^{\mathrm{IV} t}, x_{\text {jêinsp }}^{\mathrm{V} t}$, $x_{\text {jinsp }}^{\mathrm{VI} t}, x_{\text {nisp }}^{\mathrm{VII} t}, x_{\text {einsp }}^{\mathrm{VIII} t}, x_{\text {jêinsp }}^{\mathrm{IX} t}, x_{\text {jiênsp }}^{\mathrm{X} t}, x_{\text {nêisp }}^{\mathrm{XI} t}-$ they are the number of trips according to technological schemes I-XI of $s$-type vehicle (Fig. 1) during $t^{\text {th }}$ harvesting period for $r^{\text {th }}$ type of vegetables $(s=1 \ldots S, t=1 \ldots T, p=1 \ldots P) ; x_{\tau s p}-$ is the number of trips of $s$ type vehicles according to the transportation scheme $\tau$. It is calculated as the ratio of traffic volumes in a particular scheme to the performance of a particular type of road transport vehicles used:

$x_{\tau s p}=\frac{Q_{\tau}}{q_{s} \gamma_{s p}}$,

where $Q_{\tau}$ - is the volume of vegetables transportation for each transport scheme, tons; $q_{s}-$ is cargo capacity of $s$-type of vehicle, tons; $\gamma_{s p}-$ is the coefficient of load-lifting capacity utilization taking into account the workload of the $s$-type of vehicles for transportation of $r^{\text {th }}$ crop; $W_{s p}$ - is the average productivity of $s$ type of vehicles per one trip for transport of $r^{\text {th }}$ type of vegetables along each route, tons:

$$
W_{s p}=q_{s p} \gamma_{s p}, \quad \gamma_{s p}=\frac{1}{q_{s}} \min \left\{q_{s}, Q_{s} \delta_{p}\right\},
$$

where $Q_{s}$ - is workload of an $s$-type motor vehicle or a tractor, $\mathrm{m}^{3} ; \delta_{p}-$ is volume mass of the transported cargo, $\mathrm{m}^{3} / \mathrm{t}$.

The number of trips that the $s$-type of road transport vehicles can perform along each route during $t^{\text {th }}$ period is determined by the following formula:

$$
n_{s}=\frac{D \alpha T_{t s} \beta v_{\tau_{s}}}{l_{m k}+t_{l u_{s}} v_{\tau_{s}} \beta},
$$

where $l_{m k}-$ is mileage with cargo, $\mathrm{km}$.

Then, along all the routes, the required number of vehicles for the transportation of the required volume of produce in each period of harvesting is calculated with the following formulas:

$$
\begin{aligned}
& A_{\text {eisp }}^{\mathrm{II}}=\frac{x_{\text {eisp }}^{I t}\left(l_{d t}^{I}+t_{l u_{s}} \mathrm{v}_{\tau_{s}} \beta^{I}\right)}{D \alpha T_{t s} \mathrm{v}_{\tau_{s}} \beta^{I}} ; A_{\text {jinsp }}^{\mathrm{VIt}}=\frac{x_{\text {jinsp }}^{\mathrm{VI} t}\left(l_{d t}^{\mathrm{VI}}+t_{l u_{s}} \mathrm{v}_{\tau_{s}} \beta^{\mathrm{VI}}\right)}{D \alpha T_{t s} \mathrm{v}_{\tau_{s}} \beta^{\mathrm{VI}}} ; \\
& A_{j e i s p}^{\mathrm{II} t}=\frac{x_{j e i s p}^{\mathrm{II} t}\left(l_{d t}^{\mathrm{II}}+t_{l u_{s}} \mathrm{v}_{\tau_{s}} \beta^{\mathrm{II}}\right)}{D \alpha T_{t s} \mathrm{v}_{\tau_{s}} \beta^{\mathrm{II}}} ; A_{\text {nisp }}^{\mathrm{VIIt}}=\frac{x_{\text {nisp }}^{\mathrm{VII}}\left(l_{d t}^{V I I}+t_{l u_{s}} \mathrm{v}_{\tau_{s}} \beta^{\mathrm{VII}}\right)}{D \alpha T_{t s} \mathrm{v}_{\tau_{s}} \beta^{\mathrm{VII}}} ; \\
& A_{\text {jiêsp }}^{\mathrm{IIIt}}=\frac{x_{j i e \hat{s p} p}^{\mathrm{IIIt}}\left(l_{d t}^{\mathrm{III}}+t_{l u_{s}} \mathrm{v}_{\tau_{s}} \beta^{\mathrm{III}}\right)}{D \alpha T_{t s} \mathrm{v}_{\tau_{s}} \beta^{\mathrm{III}}} ; A_{\text {einsp }}^{\mathrm{VIIIt} t}=\frac{x_{\text {einsp }}^{\mathrm{VIII} t}\left(l_{d t}^{\mathrm{VIII}}+t_{l u_{s}} \mathrm{v}_{\tau_{s}} \beta^{\mathrm{VIII}}\right)}{D \alpha T_{t s} \mathrm{v}_{\tau_{s}} \beta^{\mathrm{VIII}}} ;
\end{aligned}
$$

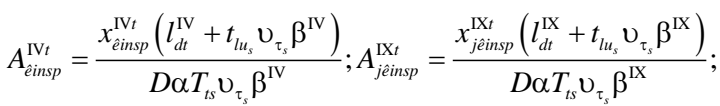

$$
\begin{aligned}
& A_{\text {jeinsp }}^{\mathrm{V} t}=\frac{x_{\text {jênnsp }}^{\mathrm{V} t}\left(l_{d t}^{\mathrm{V}}+t_{l u_{s}} \mathrm{v}_{\tau_{s}} \beta^{\mathrm{V}}\right)}{D \alpha T_{t s} \mathrm{v}_{\tau_{s}} \beta^{\mathrm{V}}} ; A_{\text {jiênsp }}^{\mathrm{X} t}=\frac{x_{\text {jiênsp }}^{X t}\left(l_{d t}^{X}+t_{l u_{s}} \mathrm{v}_{\tau_{s}} \beta^{X}\right)}{D \alpha T_{t s} \mathrm{v}_{\tau_{s}} \beta^{X}} ; \\
& A_{\text {nêtsp }}^{\mathrm{XIt}}=\frac{x_{\text {neiss }}^{X I t}\left(l_{d t}^{X I}+t_{l u_{s}} \mathrm{U}_{\tau_{s}} \beta^{X I}\right)}{D \alpha T_{t s} \mathrm{v}_{\tau_{s}} \beta^{X I}},
\end{aligned}
$$

where $\beta^{h}$-is the mileage utilization coefficient along the $h$ transportation route, $(h=1 \ldots H) ; t_{l u_{s}}-$ is the loading and unload- ing time for each vehicle of $s$-type for one run, hour; $l_{d t}^{h}-$ is the duration of a trip along the corresponding $h$ route $(h=1 \ldots H), \mathrm{km}$; $T_{t s}$-is the time of each shift, hour; $\alpha-$ is the release factor.

If we denote $a_{s}^{h t}$ by the inverse of maximum possible number of vehicles of $s$-type

$a_{s}^{h t}=\frac{1}{n_{s h}}$

along the corresponding transportation route, the formulas (2) take the following form:

$$
\begin{aligned}
& A_{\text {eisp }}^{\mathrm{I} t}=a_{s}^{\mathrm{I} t} x_{\text {êisp }}^{\mathrm{II}} ; A_{\text {jêsisp }}^{\mathrm{II} t}=a_{s}^{\mathrm{II} t} x_{\text {jêsisp }}^{\mathrm{II} t} ; A_{\text {jêssp }}^{\mathrm{III} t}=a_{s}^{\mathrm{III} t} x_{\text {jiêsp }}^{\mathrm{II} t} ; A_{\text {êinsp }}^{\mathrm{IV} t}=a_{s}^{\mathrm{IV} t} x_{\text {êinsp }}^{\mathrm{IV} t} ; \\
& A_{\text {jêinsp }}^{\mathrm{V} t}=a_{s}^{\mathrm{V} t} x_{\text {jêinsp }}^{\mathrm{V} t} ; A_{\text {jinsp }}^{\mathrm{VIt}}=a_{s}^{\mathrm{VI} t} x_{\text {jinsp }}^{\mathrm{VI} t} ; A_{\text {nisp }}^{\mathrm{VII}}=a_{s}^{\mathrm{VII} t} x_{\text {nisp }}^{\mathrm{VII} t} ; \\
& A_{\text {einsp }}^{\mathrm{VIII} t}=a_{s}^{\mathrm{VIII} t} x_{\text {êinsp }}^{\mathrm{VIII} t} ; A_{\text {jêinsp }}^{\mathrm{IXX}}=a_{s}^{\mathrm{IX} t} x_{\text {jềnsp }}^{\mathrm{IX} t} ; A_{\text {jiênsp }}^{\mathrm{X} t}=a_{s}^{\mathrm{Xt} t} x_{\text {jeênsp }}^{\mathrm{X} t} ; \\
& A_{\text {nềisp }}^{\mathrm{X} t}=a_{s}^{\mathrm{X} I t} x_{\text {nêtsp }}^{\mathrm{X} t}
\end{aligned}
$$

The transportation cost for 1 (one) ton of produce is determined by the following methods:

$$
\text { 1. } \quad C_{\tau_{s}}=\frac{C_{k m_{s}} l_{d t}^{h}}{\beta^{h} q_{s} \gamma_{s p}}+b_{s}, \text { rub }
$$

where $C_{k m_{s}}-$ is the cost of $1 \mathrm{~km}$ trip for an $s$-type vehicle, rub. $/ \mathrm{km} ; l_{d t}^{h}-$ is the duration of the trip, $\mathrm{km} ; \beta^{h}-$ is mileage utilization coefficient along $j^{\text {th }}$ transportation route; $b_{s}$ - is the coefficient, corresponding to the fixed costs for each type of vehicles, rub.

2. $C_{\tau_{s}}=\frac{C_{c h_{s}}}{W_{p t_{s}}^{h}}$, rub.,

where $C_{c h_{s}}$ - is the cost for 1 (one) hour of operation of $s$-type vehicle, rub.; $W_{p t_{s}}^{h}$ - the hourly performance of the corresponding type of vehicle along the corresponding transport route $h$ $(h=1 \ldots H)$, tons.

3. In [3] to determine the cost of transportation by tractor transport, the following formula is recommended:

$$
S_{\tau_{s}}=\frac{\sum_{i=1}^{n} r_{e i s} l_{d t}^{h}+r_{f d_{s}} T_{t s} D_{x} \alpha+r_{\hat{a}_{s}} D_{x}}{Q}\left(1+\frac{a_{g e}}{100}\right),
$$

where $l_{d t}^{h}-$ is tractor mileage for the period under consideration along the $i$-category road or in the field, $\mathrm{km} ; r_{\hat{e} i s}-$ is variable costs per unit of mileage, depending on the category of the route, rub./km; $r_{f d_{s}}-$ is fixed costs depending on time worked, rub./hour; $D_{x}-$ is the number of days in the period; $r_{\hat{\mathrm{a}}_{s}}-$ is the costs amount depending on the calendar time, rub./year; $a_{g e}-$ general expenses for the tractor transport $\left(a_{g e}=3-4 \%\right)$.

Then the total costs for cargo transportation according to the above mentioned schemes (Fig. 1) per season, rub., are as follows: 
I. $\sum_{\hat{e}=1}^{K} \sum_{i=1}^{I} \sum_{s=1}^{S} \sum_{t=1}^{T} \sum_{p=1}^{P} C_{\hat{e} i s p}^{\mathrm{I}} W_{s p} x_{\hat{e} i s p}^{\mathrm{I} t}$;

II. $\sum_{\hat{e}=1}^{K} \sum_{i=1}^{I} \sum_{s=1}^{S} \sum_{t=1}^{T} \sum_{p=1}^{P} C_{j i n s p}^{\mathrm{VI}} W_{s} x_{j i n s p}^{\mathrm{VIt}}$;

III. $\sum_{\hat{e}=1}^{K} \sum_{i=1}^{I} \sum_{n=1}^{N} \sum_{s=1}^{S} \sum_{t=1}^{T} \sum_{p=1}^{P} C_{j \hat{e} i s p}^{\mathrm{II}} W_{s p} x_{\text {jêेisp }}^{\mathrm{II} t}$;

IV. $\sum_{n=1}^{N} \sum_{i=1}^{I} \sum_{s=1}^{S} \sum_{t=1}^{T} \sum_{p=1}^{P} C_{n i s p}^{\mathrm{VII}} W_{s} x_{n i s p}^{\mathrm{VII}}$;

V. $\sum_{j=1}^{J} \sum_{i=1}^{I} \sum_{\hat{e}=1}^{K} \sum_{s=1}^{S} \sum_{t=1}^{T} \sum_{p=1}^{P} C_{j i \grave{e} s p}^{\mathrm{III}} W_{s c} x_{j i e ̂ s p}^{\mathrm{III} t}$;

VI. $\sum_{\hat{e}=1}^{K} \sum_{i=1}^{I} \sum_{n=1}^{N} \sum_{s=1}^{S} \sum_{t=1}^{T} \sum_{p=1}^{P} C_{\hat{e} i n s p}^{\mathrm{VIII}} W_{s} x_{\hat{e} i n s p}^{\mathrm{VIII} t}$;

VII. $\sum_{\hat{e}=1}^{K} \sum_{i=1}^{I} \sum_{p=1}^{P} \sum_{s=1}^{S} \sum_{t=1}^{T} \sum_{p=1}^{P} C_{\hat{e ̂ n} n s p}^{\mathrm{IV}} W_{s p} x_{\hat{e} i n s p}^{\mathrm{IV} t}$;

VIII. $\sum_{j=1}^{J} \sum_{\hat{e}=1}^{K} \sum_{i=1}^{I} \sum_{n=1}^{N} \sum_{s=1}^{S} \sum_{t=1}^{T} \sum_{p=1}^{P} C_{j e ̂ i n s p}^{\mathrm{IX}} W_{s} x_{j e ̂ i n s p}^{\mathrm{IXt}}$;

IX. $\sum_{j=1}^{J} \sum_{\hat{e}=1}^{K} \sum_{i=1}^{I} \sum_{n=1}^{N} \sum_{s=1}^{S} \sum_{t=1}^{T} \sum_{p=1}^{P} A_{j e \hat{e i n s p ~}}^{\mathrm{V}} W_{s p} x_{j e \hat{\imath} i n s p}^{\mathrm{V} t}$;

X. $\sum_{j=1}^{J} \sum_{\hat{e}=1}^{K} \sum_{i=1}^{I} \sum_{n=1}^{N} \sum_{s=1}^{S} \sum_{t=1}^{T} \sum_{p=1}^{P} C_{j i e ̂ n n s p}^{\mathrm{X}} W_{s} x_{j i e ̂ n n s}^{\mathrm{X} t}$;

XI. $\sum_{n=1}^{N} \sum_{\hat{e}=1}^{K} \sum_{i=1}^{I} \sum_{s=1}^{S} \sum_{t=1}^{T} \sum_{p=1}^{P} C_{n \hat{e} i s p}^{\mathrm{XI}} W_{s} x_{n \hat{e} i s p}^{\mathrm{XI}}$,

The most important characteristic of RCU is its daily output $Q_{i}-$ which is the maximum possible quantity of vegetables that can be processed per day (received from suppliers, sent to the consignee, taken for temporary storage) and its annual capacity. $Q_{i}^{t}-$ is the quantity of vegetables processed by $i^{\text {th }} \mathrm{RCU}(i=1 \ldots I)$ per day in the $t^{\text {th }}$ planned period $(t=1 \ldots T)$.

For MTE complex uninterrupted operation, it is necessary that the daily production of the $i^{\text {th }} \mathrm{RCU}$ is sufficient for processing all vegetables arriving during the peak harvesting period.

Based on this condition, RCU daily productivity is calculated with the following formulas:

$Q_{i}=\max Q_{i}^{t}$,

or

$$
Q_{i}=\max Q_{B B_{i}}^{t},
$$

where $Q_{B B_{i}}^{t}-$ is the quantity of vegetables delivered per day to $i^{\text {th }}$ RCU during $t^{\text {th }}$ harvesting period, tons.

Then the annual capacity of RCU is defined as the total quantity of vegetables passing through RCU during the harvesting period, and it is calculated with the following formula:

$$
Q_{i}^{t}=Q_{i} D T
$$

The total annual capacity of all RCUs should ensure processing of all kinds of agricultural produce grown in a particular region for the comprehensive range of vegetables. Therefore,

$Q=\sum_{j=1}^{J} \sum_{t=1}^{T} \sum_{p=1}^{P} Q_{i p}^{t}$

During each planned period $t, i^{\text {th }} \mathrm{RCU}$ can receive goods in quantity of $Q_{B B_{i}}^{t}$ tons (inbound), can ship $Q_{B_{i}}^{t}$ tons of vegetables (out- bound), and can keep for temporary storage $Q_{\mathrm{xp}_{i}}^{t}$ tons of produce. Consequently,

if $\quad t=1$, then $Q_{\mathrm{xp}_{i}}^{1}=Q_{\mathrm{BB}_{i}}^{1}-Q_{\hat{\mathrm{A}}_{i}}^{1}$;

if $\quad t=2$, then $Q_{\mathrm{xp}_{i}}^{2}=Q_{\mathrm{BB}_{i}}^{2}+Q_{\mathrm{xp}_{i}}^{1}-Q_{\hat{\mathrm{A}}_{i}}^{2}$;

if $\quad t=3$, then $Q_{\mathrm{xp}_{i}}^{3}=Q_{\mathrm{BB}_{i}}^{3}+Q_{\mathrm{xp}_{i}}^{2}-Q_{\mathrm{A}_{i}}^{3}$, etc.

When substitution is made, the following equations are true:

$Q_{x p_{i}}^{2}=Q_{B B_{i}}^{2}+Q_{\hat{A}_{\hat{A}_{i}}}^{1}-Q_{\hat{A}_{i}}^{1}-Q_{\hat{A}_{i}}^{2}$

$Q_{x p_{i}}^{3}=Q_{B B_{i}}^{3}+Q_{B B_{i}}^{2}+Q_{B B_{i}}^{3}-Q_{\hat{A}_{i}}^{1}-Q_{\hat{A}_{i}}^{2}-Q_{\hat{A}_{i}}^{3} \cdot$

In general,

$Q_{\mathrm{xp}_{i}}^{t}=\sum_{\tau=1}^{t}\left(Q_{\hat{\mathrm{A}}_{\hat{\mathrm{A}}_{i}}}^{\tau}-Q_{\hat{\mathrm{A}}_{i}}^{\tau}\right)$

Let us assume that $Q_{x p_{i}}^{\max }=$ const - the maximum weight of vegetables, which can be kept at RCU for temporary storage during the harvesting period, tons:

$Q_{\mathrm{xp}_{i}}^{t}=\xi Q_{i}$,

where $\xi \geq 0$ is the coefficient characterizing the fraction of vegetables quantity temporary stored at RCU depending on the capacity of RCU (it can equal to $0.1,0.3,0.8,1.3$, etc.).

Then ( $Q_{\tilde{o}_{i}}^{t} \leq Q_{\tilde{o}_{i}}^{\max }$ ) or taking into account formulas (8) and (9) the following is true:

$\sum_{\tau=1}^{t}\left(Q_{\hat{A} \hat{A}_{i}}^{\tau}-Q_{\hat{A}_{i}}^{\tau}\right) \leq \xi \max Q_{B B_{i}}^{t}$.

The quantity of vegetables brought to $i^{\text {th }}$ RCU during $t^{\text {th }}$ harvesting period is determined for each $i=1$...I according to the following formula:

$$
\begin{aligned}
& Q_{\mathrm{BB}_{i}}^{t}=\sum_{\hat{e}=1}^{K} \sum_{s=1}^{S} \sum_{p=1}^{P} W_{s p}\left\{x_{\hat{e} i s p}^{\mathrm{It}}+\sum_{n=1}^{N}\left(x_{\hat{e} i n s p}^{\mathrm{VIII} t}+A_{\text {êinsp }}^{\mathrm{IV} t}+x_{\text {êinsp }}^{\mathrm{XIt}}\right)+\right.
\end{aligned}
$$

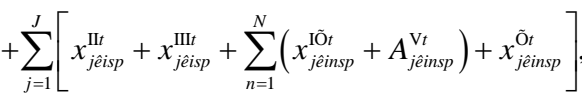

where, $A_{\text {êinsp }}^{\mathrm{VV} t}, A_{\text {jêinsp }}^{\mathrm{V} t}$ are the numbers of s-type vehicles, which are used in $t^{\text {th }}$ harvesting period at the corresponding transportation routes.

The quantity of vegetables transported through RCUs to the places where they are sold during $t^{\text {th }}$ harvesting period is determined by the following formula:

$$
\begin{aligned}
& Q_{\mathrm{B}_{i}}^{t}=\sum_{n=1}^{N} \sum_{s=1}^{S} \sum_{p=1}^{P} W_{s p}\left\{\sum _ { \hat { e } = 1 } ^ { K } \left[x_{\text {êinsp }}^{\mathrm{VIII} t}+x_{\hat{e} i n s p}^{\mathrm{IV} t}+x_{\hat{e} i n s p}^{\mathrm{X} t}+\right.\right. \\
& \left.\left.+\sum_{j=1}^{J}\left(x_{j e ̂ i n s p}^{\mathrm{r} \tilde{\mathrm{O}} t}+x_{j e \hat{e} i n s p}^{\mathrm{V} t}+x_{j e ̂ i n s p}^{\tilde{\mathrm{O}} t}+x_{j i n s p}^{\mathrm{VIt}}\right)\right]+x_{n i s p}^{\mathrm{VIIt}}\right\} \text {, }
\end{aligned}
$$

for each $i=1$...I .

Thus, preparatory work is complete for the economicmathematical optimization model creation for the process of vegetable transportation in HTS complex; and the calculation methods of the necessary basic characteristics of the process are provided. The model is based on the following postulates:

1. The delivery of vegetables from fields and plantations to RCU is advisable to carry out by tractor traction vehicles, as well as by road transport vehicles owned by agricultural enterprises. 
When farms (collective or private) experience shortage of their own vehicles, the number of necessary vehicles is calculated. The vehicles are to be recruited from other sources to be used for onfarm transport.

Optimal agricultural products producers' assignment to their recipients is a challenge, the most advantageous solution to overcome the challenge is found in two following stages, taking into account the chosen transportation technology:

a) best RCU locations are defined in the vegetable production zone, their capacity and areas of activity are determined (particular agricultural enterprises are assigned to specified RCU); b) vegetables recipients are optimally assigned to particular RCUs; required number of vehicles and their distribution for particular transportation routes are calculated.

2. The crop rotation system cannot be ignored in agricultural production. The surveys carried out by the authors draw conclusions that in irrigated agriculture regions the areas allocated for vegetables remain constant or practically unchanged from year to year, i.e. the average distance from the field to the main roads, near which RCUs can be located, remains stable as well [7, 13, 16].

Then, the logistic task is formulated as follows: it is necessary to find such a plan for supplying vehicles to all possible transportation routes so that the objective function $\mathrm{F}$ reaches its minimum value:

$$
\begin{aligned}
& F=\sum_{i=1}^{I} \sum_{s=1}^{S} \sum_{t=1}^{T} \sum_{p=1}^{P} W_{s p}\left\{\sum _ { \hat { e } = 1 } ^ { K } \left\{C_{\hat{e} i s p}^{\mathrm{I}} x_{\hat{e} i s p}^{\mathrm{It}}+\sum_{n=1}^{N}\left(\tilde{N}_{\hat{e} i n s p}^{\mathrm{VIII}} x_{\hat{e} i n s p}^{\mathrm{VIIIt}}+\tilde{N}_{\hat{e} i n s p}^{\mathrm{IV}} x_{\hat{e} i n s p}^{\mathrm{IV} t}+\tilde{N}_{\hat{e} i n s p}^{\tilde{O} \mathrm{I}} x_{\hat{e} i n s p}^{\text {OIt } t}\right)+\right.\right.
\end{aligned}
$$

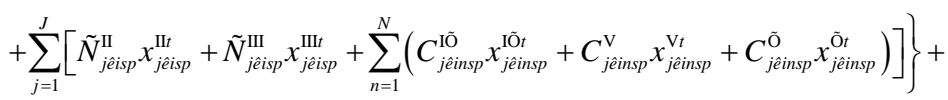

$$
\begin{aligned}
& \left.+\sum_{n=1}^{N}\left(\sum_{j=1}^{J} C_{j i n s p}^{\mathrm{VI}} x_{j i n s p}^{\mathrm{VIt}}+C_{n i s p}^{\mathrm{VII}} x_{n i s p}^{\mathrm{VII} t}\right)\right\}+\sum_{i=1}^{I} f\left(Q_{i}\right)+\sum_{i=1}^{I} z\left(Q_{i}\right) ; \\
& F \rightarrow \min .
\end{aligned}
$$

Expression 10 is obtained on the basis of formulas (7) and represents the total sum for the transportation costs of the total volume of vegetables grown in the region under consideration, taking into account investments for RCU network creation and operation $\sum_{i=1}^{I} f\left(Q_{i}\right)$ and various types losses in HTS complex $\sum_{i=1}^{I} z\left(Q_{i}\right)$.

The following conditions act as constraints in the model:

$$
\sum_{i=1}^{I} \sum_{p=1}^{P}\left[a_{s}^{\mathrm{It}} x_{\hat{e} i s p}^{\mathrm{It}}+\sum_{n=1}^{N}\left(a_{s}^{\mathrm{III} t} x_{\hat{e} i n s p}^{\mathrm{III} t}+a_{s}^{\mathrm{IV} t} x_{\hat{e} i n s p}^{\mathrm{IV} t}\right)\right]=A_{\hat{e} s}
$$

for every $\hat{e}=1 \ldots K, s=1 \ldots S, t=1 \ldots T$

$$
\sum_{i=1}^{I} \sum_{p=1}^{P}\left[\sum_{n=1}^{N}\left(a_{s}^{\tilde{O} \mathrm{O} t} x_{n e ̂ i s p}^{\tilde{\mathrm{O}} t}+a_{s}^{\mathrm{VII} t} x_{n i s p}^{\mathrm{VII} t}\right)\right]=A_{n s}
$$

for all $n=1 \ldots N, s=1 \ldots S, t=1 \ldots T$

$$
\begin{aligned}
& \sum_{i=1}^{I} \sum_{p=1}^{P}\left\{\sum_{\hat{e}=1}^{K} a_{s}^{\text {IIt } t} x_{j \hat{e} i s p}^{\text {IIt }}+a_{s}^{\text {IIIt } t} x_{j e ̂ s}^{\text {III } t}+\right. \\
& +\sum_{n=1}^{N}\left(a_{s}^{\mathrm{I} \tilde{\mathrm{O} t} t} x_{j e ̂ i n s p}^{\mathrm{I} \tilde{\mathrm{O}} t}+a_{s}^{\mathrm{V} t} x_{j e ̂ i n s p}^{\mathrm{V} t}+a_{s}^{\tilde{\mathrm{O}} t} x_{j e ̂ i n s p}^{\tilde{\mathrm{O}} t}\right)+ \\
& \left.+a_{s}^{\tilde{\mathrm{O} I t}} \sum_{n=1}^{N} x_{j i n s p}^{\tilde{O} \mathrm{I} t}\right\}=A_{j s}
\end{aligned}
$$

for all $j=1 \ldots J, s=1 \ldots S, t=1 \ldots T$.

Conditions (11)-(13) require that the demand for vegetable transportation vehicles to perform the planned deliveries is met by the existing fleet of road transport vehicles of agricultural enterprises, consignees and other identified sources of transport:

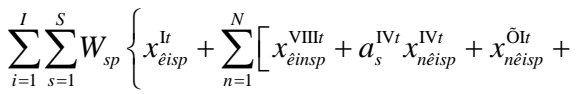

$$
\begin{aligned}
& \left.+\sum_{j=1}^{J}\left(x_{\text {jêinsp }}^{\mathrm{II} t}+a_{s}^{\mathrm{V} t} x_{\text {jêinsp }}^{\mathrm{V} t}+x_{\text {jêinsp }}^{\tilde{\mathrm{O}} t}\right)\right]+ \\
& \left.+\sum_{j=1}^{J}\left(x_{\text {jêisp }}^{\mathrm{II} t}+x_{\text {jêisp }}^{\mathrm{III}}\right)\right\}=Q_{\hat{e} p}^{t}
\end{aligned}
$$

for every $\hat{e}=1 \ldots K, s=1 \ldots S, t=1 \ldots T$

$$
\begin{aligned}
& \sum_{i=1}^{I} \sum_{s=1}^{S} W_{s p}\left\{\sum _ { \hat { e } = 1 } ^ { K } \left[x_{\hat{e} i n s p}^{\mathrm{VIII} t}+x_{\hat{e} i n s p}^{\mathrm{IV} t}+x_{\hat{e} i n s p}^{\tilde{\mathrm{O}} t}+\right.\right. \\
& \left.\left.+\sum_{j=1}^{J}\left(x_{\text {jếinsp }}^{\mathrm{I} \tilde{t} t}+x_{\text {jềnsp }}^{\mathrm{V} t}\right)\right]+\sum_{j=1}^{J}\left(x_{j i n s p}^{\mathrm{V} \mathrm{I} t}+x_{n i s p}^{\mathrm{VII} t}\right)\right\}=Q_{n p}^{t}
\end{aligned}
$$

for all $n=1 \ldots N, s=1 \ldots S+, t=1 \ldots T$.

The fulfillment of restrictions (14)-(15) ensures that, on the one hand, the total quantity of vegetables grown at all farms (collective and/or private) is shipped out, on the other hand, it guarantees the receipt of the planned quantity of products by each consignee:

$$
\begin{aligned}
& \sum_{i=1}^{I} \sum_{s=1}^{S} W_{s p}\left\{x_{\hat{e} i s p}^{\mathrm{It}}+\sum_{n=1}^{N}\left[x_{\text {êinsp }}^{\mathrm{VIIIt}}+a_{s}^{\mathrm{IV} t} x_{n e ̂ i s p}^{\mathrm{IV} t}+x_{n e ̂ i s p}^{\tilde{\mathrm{O}} t}+\right.\right. \\
& \left.\left.+\sum_{j=1}^{J}\left(x_{\text {jềnsp }}^{\mathrm{II} t}+a_{s}^{\mathrm{V} t} x_{\text {jềnsp }}^{\mathrm{V} t}+x_{\text {jềnsp }}^{\tilde{\mathrm{O}} t}\right)\right]+\sum_{j=1}^{J}\left(x_{\text {jềsp }}^{\mathrm{II} t}+x_{\text {jềisp }}^{\mathrm{II} t}\right)\right\}
\end{aligned}
$$

for anyone $i=1 \ldots I$.

Compulsory condition for optimization is the fulfillment of requirement (16), i.e the total quantity of vegetables grown in the region under consideration is transported via RCUs. If an RCU does not have enough space for long-term storage of the received goods, they are to be delivered to the recipient. If enough space is available at $\mathrm{RCU}$, a fictitious recipient with the corresponding consumption volume is introduced into expression (16), the consumption volume being equivalent to the storage space available. Providing enough storage space at RCU increases profitability and shortens the payback period for the facilities, because the cargo owners have the opportunity to sell vegetables at higher prices during off-season:

$$
\begin{aligned}
& \sum_{i=1}^{I} \sum_{s=1}^{S} W_{s p}\left\{\sum _ { \hat { e } = 1 } ^ { K } \left\{x_{\hat{e} i s p}^{\mathrm{It}}+\sum_{n=1}^{N}\left[x_{\hat{e} i n s p}^{\mathrm{IV} t}+\right.\right.\right. \\
& \left.\left.+\left(a_{s}^{\mathrm{V} t}-1\right) \sum_{j=1}^{J} x_{j e ̂ i n s p}^{\mathrm{V} t}\right]+\sum_{j=1}^{J}\left(x_{j e ̂ ́ s p}^{\mathrm{II} t}+x_{j e ̂ s i s p}^{\mathrm{IIIt}}\right)\right\}- \\
& -\sum_{n=1}^{N}\left(\sum_{j=1}^{J} x_{j i n s p}^{\mathrm{VIt}}+x_{\text {nisp }}^{\mathrm{VIIt}}\right)=0
\end{aligned}
$$

for every, $i=1 \ldots I, t=1 \ldots T$.

$\left(x_{\text {êisp }}^{\mathrm{It}}, x_{\text {jếsp }}^{\mathrm{II} t}, x_{\text {jiêsp }}^{\mathrm{III} t}, x_{\text {êinsp }}^{\mathrm{IV} t}, x_{\text {jêinsp }}^{\mathrm{V} t}, x_{\text {jinsp }}^{\mathrm{VI} t}\right.$, 
$\left.x_{n i s p}^{\mathrm{VII} t}, x_{\hat{e} i n s p}^{\mathrm{VIII} t}, x_{\text {jêinsp }}^{\mathrm{IX} t}, x_{\text {jiên } n s p}^{\mathrm{X} t}, x_{n e ̂ i s p}^{\mathrm{XI} t}\right) \geq 0$

for all $j=1 \ldots J, \hat{e}=1 \ldots K, i=1 \ldots I, \quad n=1 \ldots N, s=1 \ldots S$, $t=1 \ldots T, p=1 \ldots .$.

Condition (17) indicates that the number of trips along all the routes cannot be a negative figure.

The vector-argument in the formulated task is the number of trips by road transport vehicles that are necessary to utilize $i^{\text {th }}$ RCU design capacity, i.e. fully perform all transportations in HTS complex. It can be determined by the following formula:

$$
\begin{gathered}
X_{i}=\sum_{s=1}^{S} \sum_{t=1}^{T} \sum_{p=1}^{P}\left\{\sum _ { \hat { e } = 1 } ^ { K } \left\{x_{\hat{e} i s p}^{\mathrm{I} t}+\sum_{n=1}^{N}\left(x_{\hat{e} i n s p}^{\mathrm{VIII} t}+x_{\hat{e} i n s p}^{\mathrm{IV} t}+x_{\hat{e} i n s p}^{\mathrm{XI} t}\right)+\right.\right. \\
\left.+\sum_{j=1}^{J}\left[x_{j \hat{e} i s p}^{\mathrm{II} t}+x_{j e ̂ i s p}^{\mathrm{III} t}+\sum_{n=1}^{N}\left(x_{j e ̂ i n s p}^{\mathrm{IX} t}+x_{j e ̂ i n s p}^{\mathrm{V} t}+x_{j e ̂ i n s p}^{\mathrm{X} t}\right)\right]\right\}+ \\
\left.+\sum_{n=1}^{N}\left(\sum_{j=1}^{J} x_{j i n s p}^{\mathrm{VI} t}+x_{j i n s p}^{\mathrm{VII} t}\right)\right\}
\end{gathered}
$$

for all $i=1 \ldots I$.

HTS and RCU complexes capacities should ensure processing of all incoming vegetables during peak periods, i.e. the task of RCU rational locations determination and their capacity should be solved for HTS maximum load period.

\section{Conclusions}

Fundamental novelty and efficiency of the logistics approach to HTS complex management results in significant benefits for all logistic chain elements when the proposed model is implemented. The current level of HTS processes concentration, significant increase in transportation load require a comprehensive review of interrelated harvesting, transport and implementation processes as elements of intersectoral HTS complex in order to improve the efficiency and quality of vegetables transportation by road. As a result of given analysis, it is established that the quality of transport services for enterprises and organizations of agricultural and industrial complexes and HTS complex does not meet contemporary requirements: established terms of transportation are violated, there are losses and damage of goods during transportation. At the same time, no more than $60-70 \%$ of agricultural enterprises' motor transport is used for harvest transportation, and its performance does not improve over time.

It is established that the most rational and promising area to increase the efficiency and quality of vegetables transportation by road is the improvement of centralized management system of road transport vehicles operation (regardless their affiliation) on the basis of the intersectoral current and operational planning of HTS complex, and the choice of rational transportation schemes by creation of united technological structure of the complex.

\section{References}

[1] Napkhonenko NV (1984) Investigation of the efficiency issues and quality of vegetables transportation by road: abstract of dissertation, Candidate of Economic Sciences. M.: Moscow Institute of Managemen, p. 19

[2] Napkhonenko NV (2003) Optimization of logistical flows in "consignor-consignee" system for agricultural enterprises. Universities Messenger. North-Caucasus Region. Technical Sciences. Special Issue, pp. 141-146.

[3] Napkhonenko NV "Logistic approach to the organization of agricultural products transportation", SRSTU (NPI) Messenger. SocialEconomic Sciences Series, No. 6,( 2015), pp. 119-127.

[4] Lukinsky VS, Logistics of Motor Transport, Moscow: Finance and Statistics, (2000).

[5] Savin VI Cargo transportation by road: reference book, Moscow: "Business and Service", (2002).
[6] Savin VI Cargo transportation by road: reference book. - 2nd edition, updated and revised, Moscow: Publishing house "Business and Service", (2004), p. 544.

[7] Transportation-production processes in mechanized agricultural production // Classification, estimation and calculation methods GOST 174600-72, Moscow: Federal Standardization Committee of the Cabinet of Ministers of the USSR, (1982), p. 27.

[8] Velmozhin AV, Gudkov VA, Mirotin LB The theory of organization and management of road transport: a logistical aspect of transportation processes formation, Volgograd: RPK "Polytechnic”, (2001), p. 179

[8] Terterov MN, Leontiev AP Preparation and transportation of perishable goods, Moscow: Transport, (1983).

[10] Tatuev AA, Rokotyanskaya VV, Kiseleva NN, Zhankaziev AH, Anvarovna AS: Theoretical bases of socio-economic modernization management of the region, Social Sciences (Pakistan), (2015).

[11] Yeldashov GA "Basics for contract agreement on gargo transportation by road transport" [Text], Transport law, № 4, (2006), p. 21.

[12] Lukyanova OV, Khusainov FI "Perspectives of competition between rail and road transport", Bulletin of transport information, No. 11, (2013), pp. 3-14

[13] Goriainov OM, Roslavtsev DM Motor transport in logistic systems and chains: monograph, Kharkiv: NTMT, (2009), p. 344

[14] Nerush YM Supply and transport: effective interaction, Moscow: Economics, (1999).

[15] Zhankaziev SV, Novikov AN, Vorobyev AI, Kulev AV, Morozov DY "Efficiency of operation and functioning of the system of an indirect transport flow regulation and control", International Journal of Applied Engineering Research, 2017.

[16] Albekov AU, Parkhomenko TV, Polubotko AA “Green logistics in Russia: The phenomenon of progress, economic and environmental security", European Research Studies Journal, (2017). 